\title{
The Tree of Emotions: Exploring the Relationships of Basic
} Human Emotions

\author{
Abdel-Magid, Mohammed Isam Mohammed ${ }^{1 *}$
}

\section{ABSTRACT}

Human emotions are complex in their nature and relationships to each other. Some authors, like Shaver et al. (2001) recognized different categories of human emotions which are not linked together, i.e. they don't show how emotions in each category relate to other categories. As it would be a long and complex process to try and relate all the human emotions in a unified hierarchy, this paper deals with a restricted category of emotions known as the "basic emotions". It will discuss how those emotions can be related to each other, which ones come first and which follow, and which are more "basic" than others. This can be extended to a wider range of emotions based on the tree model suggested.

Keywords: Basic Emotions, Human Emotions, Maslow's Triangle, Categories Of Emotions, Tree Of Emotions

Human emotions are complex psychological states that consist of psychological arousal, expressive behaviors, conscious thoughts and feelings (Myers, 2010, p498). Emotions play an important role in our everyday lives, experiences and personal relations. It is hard to say how many emotions are there, some authors list 154 human emotions (Smith, 2015), while others report 135 distinct emotions (Shaver et al., 2001). The problem is more clouded by the fact that emotions differ with culture (Kagan, 1984; Myers, 2010, pp511-514) with the exception of certain emotions like fear, sadness, anger and happiness (Shaver et al., 2001).This makes it even harder to settle on a list of human emotions that is cross-cultural and agreed-upon. Even if one could provide such a complete list of emotions, the task of studying the relationships among emotion will be complex and controversial. Thus, it would be easier and to look at a subset of human emotions and study their relations, creating a model that can be extrapolated to encompass the wider emotions field.

It would be wrong to say that human emotions are a flat list that can occur in a haphazard order. It is true that the environment has an important influence on how humans develop emotions, along with other factors like cognitive, biological and social influences. For example, a child typically experiences love and affection, long before he knows the feelings

\footnotetext{
${ }^{1}$ MBBS, MRCP(UK), PgDip Diabetes, Health Assistance Medical Services, P.O. Box: 63524, Doha, Qatar *Responding Author

(C) 2017 Abdel-Magid A; licensee IJIP. This is an Open Access Research distributed under the terms of the Creative Commons Attribution License (www.creativecommons.org/licenses/by/2.0), which permits unrestricted use, distribution, and reproduction in any Medium, provided the original work is properly cited.
} 


\section{The Tree of Emotions: Exploring the Relationships of Basic Human Emotions}

of hate or envy. It can thus be said that humans develop emotions at different stages of social and behavioral development. Indeed, Shaver et al. states that knowledge about emotions is mainly developed between birth and adulthood (Shaver et al., 2001).

The idea of categorizing human emotions and trying to find relationships between emotions is not new. Shaver et al. (2001) have done a tremendous work and they grouped 135 human emotions under the six categories of love, joy, anger, sadness, fear and surprise, although they were skeptical about surprise being a separate emotional category. Still, they didn't discuss the relationships between those categories.

This paper will be dealing with what is called "basic emotions", which is a subset of the human emotions that most theorists believe are basic in all human beings (Shaver et al., 2001). It will discuss the relationships between these "basic emotions", and then apply Maslow's theory of human motivation (Maslow, 1943) to help categorize basic emotions in a tree-like structure. This will hopefully help us understand the causal and temporal relationships between human emotions and how they develop at different stages of emotional maturity.

\section{The Basic Emotions}

A well-known belief exists between emotion theorists that there are a small set of emotions known as the basic emotions (sometimes also called primary, fundamental or prototype). These emotions are considered to be the building blocks upon which other, more complex, emotions are built (Plutchik, 1980). The problem with the definition of basic emotions is that theorists have never agreed on which emotions are basic, how much of them are basic, and why some emotions are termed basic in contrast to other non-basic emotions (Ortony and Turner, 1990; Izard, 1992). The number of basic emotions has been reported by different theorists to be anything between 3 and 11 (Plutchik, 2001).

Thus, it is very difficult to construct a short list of the basic emotions that everyone agrees on. Nevertheless, Ortony and Turner (1990) have managed to assemble together the most common lists of basic emotions among theorists. Table (1), which is a modified and extended version of their work, gives a summary of some of the well-known "basic emotion" lists. Most notably, as theorists often called the same emotion with different names, the author has unified those differing names to common ones. For example, some theorists have listed happiness, while others have mentioned elation and pleasure. Those three emotions have all been substituted with joy, in line with the majority of theorists (as in Ortony \& Turner's table) who call it that way. The same was done for sorrow and grief, both of which are listed in Table (1) as sadness. In the table, Panksepp originally listed expectancy, which is the same thing as anticipation, thus it was changed to be line with the other theorists.

Some of the listed emotions can be seen as two points in the same spectrum of human emotion, if not at all the exact same emotion being mentioned in two different ways. For the sake of simplicity, those kinds of emotions were also unified in the table. For example, 


\section{The Tree of Emotions: Exploring the Relationships of Basic Human Emotions}

acceptance and subjection may be seen as two points in the same spectrum of emotion, and they have both been termed acceptance. In the same vein, Anxiety and distress have both been referred to as anxiety. Also, rage and anger will both be called anger all through the discussion.

Some researchers have displayed concern about regarding interest (Ekman, 1992; Ortony \& Turner, 1990) and shame (Ekman, 1992) in the basic emotions list. As both have been listed by other theorists, they are included in Table (1).

Table (1): Lists of Basic Emotions by theorists (Ortony and Turner 1990)

\begin{tabular}{|l|l|}
\hline Theorist(s) & Basic emotions (N) \\
\hline Arnold & $\begin{array}{l}\text { Anger, aversion, courage, dejection, desire, despair, fear, hate, hope, love, } \\
\text { sadness (11) }\end{array}$ \\
\hline $\begin{array}{l}\text { Ekman, Friesen } \\
\text { \& Ellsworth }\end{array}$ & Anger, disgust, fear, joy, sadness, surprise (6) \\
\hline Frijda & Desire, joy, interest, surprise, wonder, sadness (6) \\
\hline Gray & Anger and terror, anxiety, joy (3) \\
\hline Izard & $\begin{array}{l}\text { Anger, contempt, disgust, anxiety, fear, guilt, interest, joy, shame, surprise } \\
(10)\end{array}$ \\
\hline $\begin{array}{l}\text { Jack, Garrod \& } \\
\text { Schyns (2014) }\end{array}$ & joy, sadness, fear, surprise, disgust, anger (6) \\
\hline James & Fear, sadness, love, anger (4) \\
\hline McDougall & Anger, disgust, joy, fear, acceptance, tender-emotion, wonder (7) \\
\hline Mowrer & Pain, joy (2) \\
\hline $\begin{array}{l}\text { Oatley \& } \\
\text { Johnson-Laird }\end{array}$ & Anger, disgust, anxiety, joy, sadness (5) \\
\hline Panksepp & Anticipation, fear, anger, panic (4) \\
\hline Plutchik & Acceptance, anger, anticipation, disgust, joy, fear, sadness, surprise (8) \\
\hline Shaver et al. & love, joy, anger, sadness, fear, surprise (6) \\
\hline Tomkins & Anger, interest, contempt, disgust, anxiety, fear, joy, shame, surprise (9) \\
\hline Watson & Fear, love, anger (3) \\
\hline $\begin{array}{l}\text { Weiner \& } \\
\text { Graham }\end{array}$ & joy, sadness (2) \\
\hline
\end{tabular}

Jack, Garrod and Schyns (2014), based on their experiment on facial expressions, stated that there are only four emotional categories: happy, sad, fear/surprise, and disgust/anger. Even though they regarded four emotions are two, they still listed them, and so is shown in Table (1). 
Putting all of the above-mentioned lists together, one can come up with a list of 25 distinct basic emotions. Table (2) cross-references those basic emotions with the theorists who listed them. It can be seen from the table that there is no one emotion that is universally agreed upon by theorists as being a "basic emotion". The most widely accepted basic emotions, in descending order, are (number in braces are counts of theorists who agree on the emotion, out of a total of 16): anger (13), joy (12), fear (10), and sadness (9).

Table (2): Summary of the Basic Emotions as listed by different theorists

\begin{tabular}{|c|c|c|c|c|c|c|c|c|c|c|c|c|c|c|c|c|}
\hline Basic emotion & A & $\mathbf{E}$ & $\mathbf{F}$ & G & I & Jc & $\mathbf{J m}$ & Mc & Mo & 0 & $\mathbf{P a}$ & Pl & $\mathrm{S}$ & $\mathbf{T}$ & Wa & We \\
\hline Acceptance & & & & & & & & + & & & & + & & & & \\
\hline Anger & + & + & & + & + & + & + & + & & + & + & + & + & + & + & \\
\hline Anticipation & & & & & & & & & & & + & + & & & & \\
\hline Anxiety & & & & + & + & & & & & + & & & & + & & \\
\hline Aversion & + & & & & & & & & & & & & & & & \\
\hline Contempt & & & & & + & & & & & & & & & + & & \\
\hline Courage & + & & & & & & & & & & & & & & & \\
\hline Dejection & + & & & & & & & & & & & & & & & \\
\hline Desire & + & & + & & & & & & & & & & & & & \\
\hline Despair & + & & & & & & & & & & & & & & & \\
\hline Disgust & & + & & & + & + & & + & & + & & + & & + & & \\
\hline Fear & + & + & & & + & + & + & + & & & + & + & + & + & + & \\
\hline Guilt & & & & & + & & & & & & & & & & & \\
\hline Hate & + & & & & & & & & & & & & & & & \\
\hline Hope & + & & & & & & & & & & & & & & & \\
\hline Interest & & & + & & + & & & & & & & & & + & & \\
\hline Joy & & + & + & + & + & + & & + & + & + & & + & + & + & & + \\
\hline Love & + & & & & & & + & & & & & & + & & + & \\
\hline Pain & & & & & & & & & + & & & & & & & \\
\hline Panic & & & & & & & & & & & + & & & & & \\
\hline Sadness & + & + & + & & & + & + & & & + & & + & + & & & + \\
\hline Shame & & & & & + & & & & & & & & & + & & \\
\hline Surprise & & + & + & & + & + & & & & & & + & + & + & & \\
\hline Tender-emotion & & & & & & & & + & & & & & & & & \\
\hline Wonder & & & + & & & & & + & & & & & & & & \\
\hline
\end{tabular}

Key: (A) Arnold, (E) Ekman, Friesen \& Ellsworth, (F) Frijda, (G) Gray, (I) Izard, (Jc) Jack, Garrod \& Schyns, (Jm) James, (Mc) McDougall, (Mo) Mowrer, (O) Oatley \& Johnson-Laird, (C) The International Journal of Indian Psychology, ISSN 2348-5396 (e)| ISSN: 2349-3429 (p) | 25 
(Pa) Panksepp, (Pl) Plutchik, (S) Shaver et al., (T) Tomkins, (Wa) Watson, (We) Weiner \& Graham.

It can also be seen from Table (2) that some basic emotions have been mentioned by only one theorist, Arnold. Those isolated entries include aversion, courage, dejection, despair, hate, hope, pain and tender-emotion. It is very difficult to grasp the exact meaning of McDougall's "tender-emotion", as the term itself is not well defined and is very loose. In the course of this discussion, it has been treated as a remote synonym to love, and it will not be further mentioned as a separate emotion.

Although aversion and hate are listed as two different emotions, they are essentially the same thing. Hate might be seen as a stronger word for aversion, the latter being more of a general "dislike" or "distaste" of something, a feeling that can grow in intensity to the point of hatred. For this reason, those two emotions, while listed separately in Tables (1) and (2), are treated as the same emotion (hate) in the course of this discussion. The same can be said about dejection and sadness, as the former is essentially strong feeling of sadness, possibly to the point of depression.

\section{The Hierarchy of Human Emotions}

In his discussion about the theory of human motivation, Maslow (1943) has argued that human needs are arranged in the form of "hierarchies of pre-potency". What that means is that in order for a human-being to feel a given need, he must first satisfy another, more "prepotent" need. Without satisfying the latter, more primitive need, the former need will never be satisfied, simply because it will never exist in the first place. Furthermore, Maslow states that "... no need or drive can be treated as if it were isolated or discrete; every drive is related to the state of satisfaction or dissatisfaction of other drives" (Maslow, 1943, p370). This means that all human needs and desires form a coherent network, with each need or desire being connected to other needs and desires, and the overall layout of that network is in the form of a hierarchy. Furthermore, Maslow (1943) states that the physiological needs (e.g. hunger, thirst, sex) are the most basic of all human needs. This is why those needs must be satisfied first, before the less basic needs are tended for. Once the basic needs are satisfied, e.g. being well-fed, a new set of "higher" needs appear, and those become the new driving force for the human-being.

The human needs that Maslow discusses in his work do not manifest themselves directly, but rather indirectly by inducing certain feelings or emotions in the human-being, and acting as fuel for motivation. Thus, it can be said that for each basic human need there is a corresponding emotion (or group of emotions) that manifests itself in order for the individual to satisfy that need. On the other hand, for each basic human emotion there is a corresponding need (or multiple needs) that must be satisfied. This means that Maslow's layers of human needs can be taken as a rough guide to the map of human emotions. 
One can take the above ideas, which Maslow entertained as part of his theory of human motivation, and apply a similar paradigm to basic human emotions. That is, one can say that all human emotions are connected in a network, and that this network can be viewed in the form of a hierarchy. At the heart of this hierarchy are the basic human emotions, on top of which other, more complex, emotions develop and depend. If one would go a step further, it could be said that in order to develop a certain emotion, or have the capacity to feel such an emotion, one must first develop all of the other emotions which "lie below" this particular one in the hierarchy of human emotions.

Applying Maslow's concept to basic emotions, one can say that basic human emotions are not all equally "basic". Some emotions are more "basic" or "low level", while others are more "high level". In order for the human-being to be able to experience the "high level" emotions, he must first go through the "low level" emotions and experience them. For example, one can not develop the capacity to love or feel happiness before first experiencing the feelings of hunger and thirst, which are more basic and innate in human nature.

In that sense, basic emotions can be divided into five levels, in line with Maslow's five levels of human needs. Figure (1) shows the levels of basic human emotions, along with the corresponding level of needs in Maslow's model shown on the left. The pyramid should be read from the bottom-up, as is going to be discussed in the following sections.

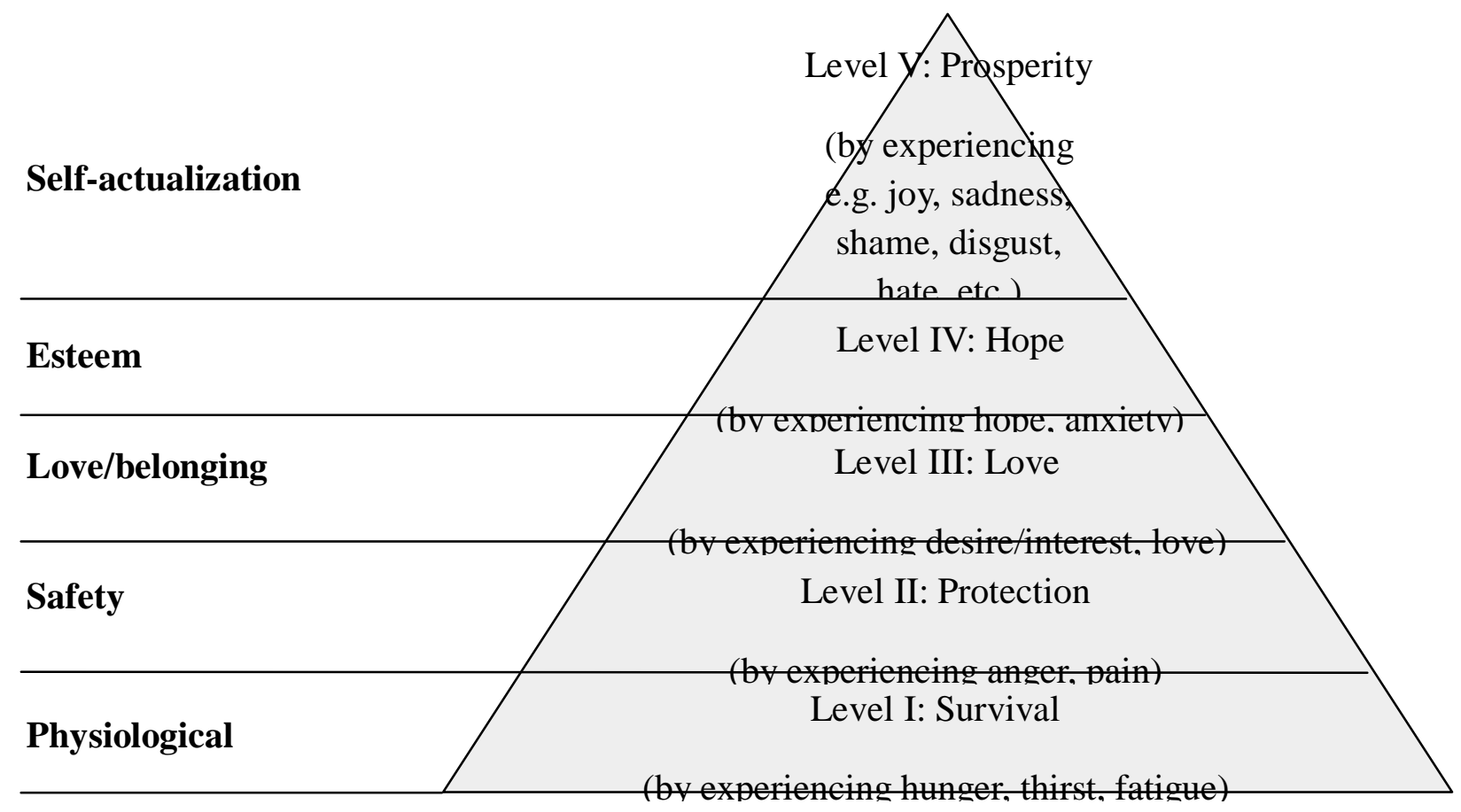

Figure (1): Levels of basic emotions modeled after Maslow's basic needs 


\section{LEVEL I: SURVIVAL}

In the early stages of human development, human needs were basic, consisting mostly of the physiological needs like the need for food, water and sleep. During this stage of human development, the basic emotions that humans could experience were closely linked to those basic needs. That is, the feeling of hunger was triggered by being hungry, which is a direct physiological response to the fact that the body needs nutrients and energy. Similarly, being thirsty is a direct physiological response to the body need for water in order to survive. This idea is not new, as Plutchik (1980) has stated in his psycho evolutionary theory of emotion that "emotions serve an adaptive role in helping organisms deal with key survival issues posed by the environment" (Plutchik, 1980, p8). It can thus be said that at this level, all the basic emotions that humans are able to experience are those that relate directly to survival. The higher levels of human emotions are considered luxurious and secondary at this point. They are basically non-existent.

Human-beings, like all other living organisms, need (1) to survive as individuals, and (2) to reproduce in order to save the species from extinction. The first function is tended for by the "physical needs" layer of Maslow's model (Maslow, 1943). The second function can only be carried out through sexual reproduction in humans. One can thus say that sex is another "basic need" that is met by the corresponding feelings of physical attraction to the other sex. At this point, love has no role in the process of reproduction and saving the human species, as it has never existed thus far. The process of having sex at this level is strictly physiological and is not different from what is practiced by other species. This idea (of love vs sex) has been entertained by Maslow who states that "love is not synonymous with sex", and that "sex may be studied as a purely physiological need” (Maslow, 1943, p381).

\section{LEVEL II: PROTECTION}

Maslow states that after the basic physical needs are satisfied and catered-for, human-beings start to develop more "higher" needs, that is, safety needs (Maslow, 1943). Those are the needs for a safe home, safe environment, safe life and family, and so on.

In the presented model, it can be said that after developing the basic emotions of survival, humans then start developing and experiencing level II emotions, which are concerned with safety and protection. Those emotions build on the previous level emotions, and occur as a direct result of them.

For example, say that a person was hungry. This basic emotion of feeling "hunger", which is a level I (survival) emotion, is a direct result of the body system reporting loss of one (or several) types of nutrients and/or minerals. If that hunger is not satisfied, the only channel through which one could proceed would be by feeling pain. Whether it be somatic pain, like hunger cramps or abdominal pain; or emotional pain and strife, like feeling dizziness or lightheaded, the only feeling one could have at this point is pain. Thus, the emotion of pain could not be felt without first experiencing one or more of level I emotions, e.g. thirst, hunger, fatigue, etc. 
Now let's say that this hungry human-being could not find food to control his hunger. That, by extension, means that the feeling of pain, that originally resulted from the feeling of hunger, will not be controlled. Now this human-being needs to develop a new emotion in order to reflect the new state of feeling he is in. The only emotion that can result from the feeling of pain is the feeling of anger. That human-being will now be in a state of anger for not being able to satisfy his hunger needs, which resulted in pain that he couldn't suppress. This state of anger can culminate in frustration and agony, among many other feelings. We are not going to list all the possible emotions here, as we are concerned with only the basic human emotions, as listed by the different theorists (see Tables 1 \& 2).

But one could argue that this hungry human-being, who felt pain, followed by anger due to his failure to satisfy that basic need, could eventually develop acceptance, despair, sadness, fear (e.g. of death), and so on. And it is a good argument, but not totally logical or true. For the desperate human-being who is starving to death, who is angry and is frustrated, acceptance is never a valid option, for accepting his current situation means succumbing to certain death. Also, fear of death cannot be experienced yet, as the individual has not fully developed at the emotional level in order to experience such a complex feeling. He will certainly feel that he doesn't want to perish, but this innate and shapeless feeling could hardly be termed fear at this point. Fear is a feeling that is experienced by human-beings when they reach a certain level of sophisticated emotional development.

To illustrate this point, let's talk about some of the specific fears that humans usually experience, like arachnophobia, ophidiophobia, and acrophobia; which stand for the fear of spiders, snakes and heights, respectively. People living in forests and in "less developed" societies don't jump when they see a spider. They might have a reaction of fighting, steppingon, chasing \& hunting, etc., but fear is never an option. Those "less developed” people don't fear spiders because they don't know what fear is, they didn't reach the level of emotional maturity that is required to experience such an emotion. Likewise, children don't feel fear when they see a spider. They might feel intrigued, curious, or may think it's a toy or some funny object, nothing more. Those “less developed” individuals also didn’t develop the capacity to experience a high level emotion like fear. The same could be said about snakes. Less developed people would see it as a threat to their lives, could think of large snakes as potential food, could worship it because of its beauty and might, but would not experience fear from snakes in the sense of fear that is seen in the "more developed" societies. Those same people will regard high places a good shelter from predators and may actually prefer sleeping on a tree branch, not feeling "fear" of falling down, unlike the more "developed societies” where acrophobia is seen.

This level of human emotion is called protection, because two basic emotions of that level, pain and anger, are a direct extension to level I emotions, the ones that are directly related to survival. In this level, pain and anger are emotions that develop from the need of the humanbeing to guard his life, livelihood and the species as a whole. 


\section{LEVEL III: LOVE}

Having experienced the feelings of the previous two levels, and being safe and satisfied, the typical human-being will turn around and search for social interaction with family, friends and society at large. That is to say, after having the capacity to feel pain and anger, the human-being is now ready to develop the next level of emotions, and that is centered around love and belonging.

This level starts with the feeling of desire or interest. human-beings want to have friends they can talk to and keep them company. They want to have a life companion, be it male or female, with which to share good times and bad times. They want to have the support of their parents and siblings. They want to be part of something bigger, a society or a fight for certain cause, for example. All of these things start by showing a desire to have the relationship with someone, or to be in possession of something. It can also be said to happen when someone shows an interest in something or in someone else.

It can be seen from Table (2) that Arnold and Frijda have listed desire, while each of Frijda, Izart and Tomkins have listed interest as one of the basic emotions. Moreover, Frijda considers desire and interest to be separate human emotions, which they certainly are. But it can be argued that the two are different strengths of the same basic emotion, with desire being interest that is stronger and is accompanied by wanting the thing of interest physically. For this reason, both desire and interest are treated as two related emotions at the same level, as will be seen in Figure (2). That doesn't mean the two emotions are mutually exclusive, as an individual might experience one or the other, or both of the two at the same time. 


\section{LEVEL V: PROSPERITY}
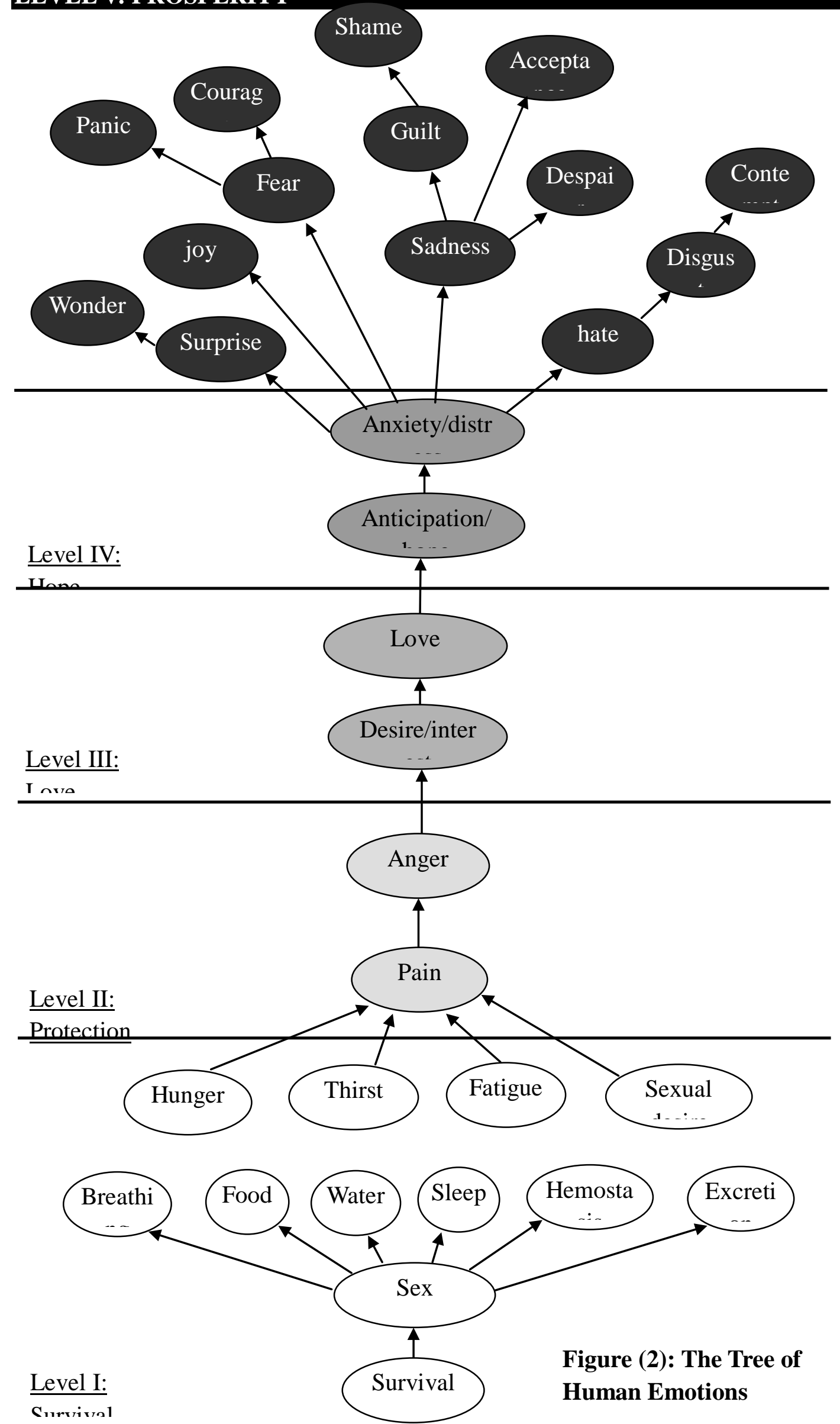

(c) The International Journal of Indian Psychology, ISSN 2348-5396 (e)| ISSN: 2349-3429 (p) | 31 


\section{The Tree of Emotions: Exploring the Relationships of Basic Human Emotions}

As Maslow (1943) points out, love is a two-way road, as it involves both giving and receiving. This is why love can be seen as the first human emotion that is really "high level", as it needs more than one individual in order to develop. One can not speak about love between one and oneself. Even selfishness, or the love of oneself, is an emotion that develops after first having the capacity for loving others. In some cases it might even happens as a reaction for being rejected and not having the love one was reaching for.

So in order for the human-being who have shown desire or interest in someone or something to develop the emotion of love, there must be reciprocal interaction from the other side. This reaction could be positive or negative, but either way it must happen in order for the humanbeing to progress from desire/interest to developing the emotion of love.

Let's take an example to demonstrate the progression from desire/interest to love. Say that a boy showed an interest in a girl. If she shows him a similar interest, he would go through different emotions until he reaches joy and happiness. If she rejects him, he might go on to develop sadness, hate or anger. If she doesn't respond to his request, he might take this as rejection and follow the same path. If, on the other hand, he tries to contact her but she isn't answering him, he would go through the path of questioning and wonder. In any of these cases, there was an interaction between two human-beings, and this interaction led eventually to the emotional development of the boy, taking him through levels III to $\mathrm{V}$ in our emotions model (see Figure 2).

But let's consider the possibility that the boy didn't show the girl his desire/interest, because he couldn't reach her. Say, for example, the boy is interested in his favorite movie star and he has a poster of her in his room. Not being able to have a direct or indirect interaction with the subject of interest, the boy could never proceed from desire/interest to love. That is, he will be stuck in the desire/interest step at level III. He could never ascend to the higher levels, thus never being able to develop the higher emotions in the hierarchy. Also, what he experiences can never be termed love, as there is only one party in an emotion that needs more than one.

\section{LEVEL IV: HOPE}

In Maslow's theory of human motivation, satisfaction of the needs of love and belonging results in the appearance of the needs of esteem. This includes both internal (e.g., confidence, personal achievements) and external (e.g., respect by others) esteem (Maslow, 1943).

In our model, having attained the milestone of love in the previous level is important in order for the individual to progress to the next level. For example, a couple have gone through the stages of showing interest to being in love. Their emotional development will certainly not stop at this step, but will develop forward. The next step would be for them to hope (or anticipate) for external things like getting pregnant and having an offspring, getting a new job or a promotion, winning a case, etc. The sense of hope (or anticipation) could also be internal, like the hope that the other person will bring joy and happiness to one's life, for example. 


\section{The Tree of Emotions: Exploring the Relationships of Basic Human Emotions}

Referring back to Table (2), it can be seen that Plutchik listed anticipation as one of the basic emotions, while Arnold listed hope. None of the other theorists in Table (2) have listed either of those two emotions. Both of the two can be seen as points in the same spectrum of emotion. Anticipation is predominantly negative or neutral. It is the feeling of waiting for something to happen, while expecting negative results (or failure). Hope, on the other hand, is also waiting for something to happen, but the expectation here is for positive results (or success). It would be wrong to say that the two emotions are the same, as they are not. Still, it would be difficult to treat them as completely separate entities, because they both have the same core feeling of "waiting for something”. Thus, both anticipation and hope are treated as two related emotions at the same level, as can be seen in Figure (2).

Let's take our previous example, of the boy who showed an interest in a girl. If there was no way for him to contact her at all, he will be stuck in the desire/interest step. If, on the other hand, there was any form of interaction, the boy would go on to the step of deep affection, which will eventually culminate in love. The step at love is almost always a short-lived one, and humans almost always move forward to acquire new emotions at higher levels. That doesn't mean the emotion of love is lost, it only means that the capacity to feel love is critical in order for the individual to have the ability to develop other emotions. Feeling love is thus important to unlock the higher levels of human emotion, both positive and negative ones.

So the boy feels love for the girl, what is the next emotion he will develop? He will never jump directly to joy or sadness. He must first experience hope (if he is optimistic) or anticipation (if he is pessimistic) while waiting for her answer. This will unlock another feeling, that is of anxiety or distress, while waiting. The transition between those emotions could be very fast or very slow, but they would be experienced to some degree in all cases.

The above example was about anticipation/hope for internal events. What about anticipation/hope for external events? The same principles hold. If one is hoping to get a job, or anticipating a salary raise, one must first show desire/interest in the company, then feel love for his job and his company, then reach the step of anticipation/hope. One doesn't anticipate things from people (or establishments) one doesn’t love or care about.

\section{LEVEL V: PROSPERITY}

The term prosperity is used here to mean the state of being "emotionally diverse". In other words, having the capacity to feel any number of different emotions, most of which are "high level", in the sense that they need the development of "low level" emotions before they could be reached.

The human-being who reached the level of prosperity is the one who have experienced the basic emotions of hunger, thirst, fatigue, and so on. It is the one who could feel pain and anger as a direct result of the basic "physiological" emotions. It is the one who could show desire/interest in other people/things/society, and who could eventually feel love and being loved in return. It is the one who could anticipate and hope for things to happen, and who 


\section{The Tree of Emotions: Exploring the Relationships of Basic Human Emotions}

could experience anxiety and distress from that anticipation.

Just as Maslow (1943) says that the emergence of self-actualization and creativity needs only happens after all the physiological, safety, love and esteem needs are satisfied; one can say that the full spectrum of human emotions can't be attained without passing through the first four levels and developing the capacity to experience the emotions contained therein. Upon reaching the level of prosperity, one can take any number of different paths.

Let's take the example of the boy and the girl once more. Let's say that the girl rejected the boy without giving any reasons whatsoever. The boy would then feel surprised as he didn't expect this response. He would almost certainly wonder why this was the response he got from the girl (see Figure 2). From here on, there are dozens of possibilities that are not going to be discussed, as we are trying to stick to our list of basic emotions.

But if the girl rejected the boy and gave her reasons, the boy could take any one of different paths (see Figure 2). He could fall into despair, trying to contact her and talk her into liking him. She would probably refuse again, with him feeling sadness or sorrow. He could reach the understanding that he can't do anything about it, and that will result in acceptance or subjection. Or he could think that he did something wrong, or that he was not adequately sufficient, and this could result in the feeling of guilt, which could progress to the feeling of shame. In the extreme case, the boy could directly progress from the stage of anxiety/distress to develop the emotion of aversion or hate for the girl who rejected him. If the boy is really insulted, or deeply affected by the rejection, this could progress to the feeling of disgust, which can then culminate in contempt for the girl who rejected him.

If the girl accepts the boy's love, the path is very short, as the boy will immediately experience happiness (or joy).

In some cases, the feeling of anxiety/distress could propagate to the point that one will feel fear. As was discussed under level II (protection), fear is one of the "higher level" basic human emotions. It is an emotion that can only be experienced when an individual has reached the level of emotional prosperity. It can be seen as a luxury that humans who are emotionally “less developed” cannot experience.

If one cannot control the emotion of fear or remove its cause, this emotion can grow further and result in another emotion, panic, which will normally be associated with some physical escape response. On the other end of the spectrum, if one could control fear and remove its precipitant, this will result in courage, which could be seen as the absence of fear, or the control of that fear. Either way, courage is defined in terms of fear, which means one cannot experience courage without first experiencing fear. Facing a deadly snake without knowing it's deadly is not courage, but rather ignorance. Facing the same deadly snake while knowing exactly what one is fighting, and quenching the fear of a faster, stronger and sometimes a larger animal, is courage. 


\section{The Tree of Emotions: Exploring the Relationships of Basic Human Emotions}

\section{Shortcomings of the Hierarchy}

The above discussion about the hierarchy of basic human emotions does give an overview of how those emotions could be related to each other, and to Maslow's layers of human needs (see Figure 1).

One problem with Figure (1) is that the base of the triangle, which contains level I emotions (the ones related to survival) is wider. This gives the impression that level I emotions are more diverse and variable than level V emotions, which is the opposite of what's true.

Another problem is that the shape gives the impression that the five levels of basic human emotions are completely separate from each other, which is also not true. One can traverse the levels in both directions, up and down, provided that he starts from the bottom layer at the begging.

To better visualize the structure of the above-mentioned hierarchy and remedy its shortcomings, it would be more appropriate to think of human emotions in the form of a treelike structure, as shown in Figure (2). In this figure, it can be seen that the tree starts from its roots, which is composed of level I emotions, that form a bulb underground. All of the emotions at this level are innate or "built-in", this is why they are found underground, just like the roots of a tree are hidden under the soil. They are also related to direct physiological needs (shown also in Figure 2), and are directly related to sex, which is the only mode of survival for the human species.

Having experienced those basic emotions, one transcends upwards, like a tree bud emerges from under the soil. This brings us to level II, which contains two strong and crude emotions: pain and anger. This level, being narrow as it is, forms the base of the trunk of our tree.

The next level is level III, which contains two emotions: desire/interest and love. As discussed under the heading "Level III: Love”, both desire and interest are treated as one in the course of this discussion. This level forms the central part of the tree trunk.

The upper part of the trunk is formed by level IV emotions. Those are anticipation/hope and anxiety/distress. Those pairs of emotions are treated as the same for the sake of this discussion.

Level V, prosperity, is the final and topmost level. It can been seen as the branches and leaves of the tree. The branches consist of "intermediate" basic emotions like surprise, despair and hate; while the leaves are formed by the more "terminal" emotions like shame, panic, courage and contempt. This level is endless, as more and more emotions can be added, forming more branches and budding new ending leaves.

What the tree aims to show is that the basic human emotions are not all equally "basic". Some emotions form the root for others. By contrast, some emotions depend on others, i.e. to 


\section{The Tree of Emotions: Exploring the Relationships of Basic Human Emotions}

be able to experience an emotion, one would need to first experience the "lower level" emotions. Thus, without knowing love, one can never know guilt or joy; without pain, there would be no anger; without hope, one would never develop fear or hate; and so on.

The other thing is that the arrows in Figure (2) show the original direction through which humans pass the first time they traverse this tree. That means one must start at the root and walk one's way to the top. At any point, one can go down to experience any emotion in the lower levels, and then come back up to the last level one had reached. In other words, after "unlocking” an emotional level, one can go up and down through the tree levels.

The other thing is that once a higher level is "unlocked", one can jump between this level and the lower levels without traversing the tree. For example, one could jump from anger to surprise, provided that he had already "unlocked" level V beforehand by walking up the tree. That is, one must have visited levels I, II, III, IV and V at some previous point.

\section{Extending the basic emotions tree}

Shaver et al. (2001) identified six "basic-level" categories, which can be considered as their list of basic emotions, although the authors didn’t call them "basic emotions” per se. Instead, they mentioned the striking similarity and overlap between their basic categories and the basic emotions lists of most of the emotion theorists. Those basic categories were: love, joy, anger, sadness, fear, and surprise (which was questioned as one of the basic-level categories as its contents were small and because of its poor appearance in the emotion literature) (Shaver et al., 2001).

Therefore, one can easily fit the categories of Shaver and his colleagues onto our tree. It can be seen from Figure (2) that the six basic-level categories of Shaver et al. appear as branches in the tree. One can then extend the tree to add secondary branches that are composed of Shaver et al.'s secondary emotions. Those can be extended further to accommodate their tertiary emotions as terminal leaves to the tree of basic human emotions.

\section{CONCLUSION}

By relating to the hierarchy in Maslow's theory of human motivation (Maslow, 1943), a 5 layered model is constructed that shows the possible relationships between the "basic emotions" of human beings. Emotions at the lowest level develop as a direct response to basic human needs, and are important for survival. These basic emotions include hunger, thirst, fatigue and sexual desire. Those emotions are related to the "physiological needs" in Maslow's hierarchy, upon which all the other needs depend for development.

The second level contains emotions that are related to protection (of the lower level needs) as include pain and anger. The third level contains emotions of desire (or interest) and love. The fourth level contains emotions hope and anxiety. The fifth and topmost level is the level of emotional prosperity. It is in this level that most of the human emotions flourish and fully develop. 
The above is a model for the restricted group of human emotions known as the "basic emotions”. Those are the emotions believed by most theorists as universal and cross-cultural. Nevertheless, the model can be extended to accommodate more emotions.

\section{REFERENCES}

Ekman, P. (1992). Are there basic emotions? Psychological Review, 99(3), 550-553.

Izard, C.E. (1992). Basic emotions, relations among emotions, and emotion-cognition relations. Psychological Review, 99(3), 561-565.

Jack, R.E, Garrod, O.G. \& Schyns, P.G. (2014). Dynamic Facial Expressions of Emotion Transmit an Evolving Hierarchy of Signals over Time. Current Biology, 24(2), 187192. doi: http://dx.doi.org/10.1016/j.cub.2013.11.064.

Kagan, J. (1984). The nature of the child. New York, NY: Basic Books.

Maslow, A. (1943). A Theory of Human Motivation. Psychological Review, 50(4), 370-396.

Myers, D. G. (2010). Emotion, stress, and health. Psychology: Ninth Edition. New York, NY: Worth Publishers.

Ortony, A. \& Turner, T.J. (1990). What's basic about basic emotions?. Psychological review, 97(3), 315-331.

Plutchik, R. (1980). A general psychoevolutionary theory of emotion. In R. Plutchik \& H. Kellerman, Emotion: Theory, Research and Experience, Volume I (pp. 3-12). New York, NY: Academic Press, Inc.

Plutchik, R. (2001). The Nature of Emotions: Human emotions have deep evolutionary roots, a fact that may explain their complexity and provide tools for clinical practice. American Scientist, 89(4), 344-350. Retrieved from http://www.jstor.org/stable/27857503.

Shaver, P., Schwartz, J., Kirson, D., \& O'Connor, C. (2001). Emotional Knowledge: Further Exploration of a Prototype Approach. In G. Parrott (Eds.), Emotions in Social Psychology: Essential Readings (pp. 26-56). Philadelphia, PA: Psychology Press.

Smith, T.W. (2015). The book of human emotions: An Encyclopedia of Feeling from Anger to Wanderlust. London, UK: Profile Books Ltd.

How to cite this article: Abdel-Magid, MI (2017). The Tree of Emotions: Exploring the Relationships of Basic Human Emotions. International Journal of Indian Psychology, Vol. 5, (1), DIP: 18.01.123/20170501, DOI: 10.25215/0501.123 